\title{
A IMPLANTAÇÃO DE UM MODELO DE GESTÃO DE PESSOAS COM BASE NA GESTÃO POR COMPETÊNCIAS EM UMA INSTITUIÇÃO DE ENSINO SUPERIOR PRIVADA
}

\author{
THE IMPLEMENTATION OF A HUMAN RESOURCES MANAGEMENT MODEL BASED ON THE \\ COMPETENCY-BASED MANAGEMENT IN A PRIVATE HIGHER EDUCATION INSTITUTION
}

\author{
LARISSA NARDES \\ Graduada em Administração e Mestranda em Administração \\ Programa de Pós-Graduação em Administração - Faculdade Meridional (IMED) \\ Orcid: http://orcid.org/0000-0003-1109-7728 / E-mail: Inardesn@gmail.com \\ Rua Senador Pinheiro, 304 - Passo Fundo/RS, CEP: 99070-220
}

\section{SHALIMAR GALLON}

Doutora em Administração com ênfase em Gestão de Pessoas

Programa de Pós-Graduação em Administração - Faculdade Meridional (IMED)

Orcid: http://orcid.org/0000-0002-8830-4433 / E-mail: shalimargallon@gmail.com

\author{
ELAINE TAUFER \\ Mestre em Administração - Faculdade Meridional (IMED) \\ Consultoria de Gestão de Pessoas
}

Orcid: http://orcid.org/0000-0003-2425-1421 / E-mail: elaine.taufer@gmail.com

\section{BETINA MAGALHÃES BITENCOURT}

Universidade Estadual do Rio Grande do Sul (UERGS)

Titulação: Doutora em Administração com ênfase em Gestão de Pessoas

Orcid: http://orcid.org/0000-0002-6830-8429 / E-mail: betina.mb@gmail.com

Submissão: 09/07/2020. Revisão: 08/11/2020. Aceite: 29/12/2020. Publicação:01/03/2021. DOI: http://dx.doi.org/10.22277/rgo.v14i2.5644

\section{RESUMO}

As Instituições de Ensino Superior (IES) brasileiras estão buscando a implantação de novas estratégias a fim de se diferenciar dos seus concorrentes. Um modelo que tem tido destaque na Gestão de Pessoas (GP) é o de gestão por competências, visto que este tem sido apontado como um modelo que aproxima a GP da gestão estratégica. Este estudo, por conseguinte, tem como objetivo analisar o desenvolvimento e a implantação de um modelo de GP com base na gestão por competências em uma IES privada. A presente pesquisa é um estudo de caso qualitativo realizado em uma IES privada por meio de seis entrevistas e análise de documentos da IES. Os resultados mostram que o modelo facilitou a tarefa de gerenciar, possibilitando mais justiça e coerência no trato com as pessoas, eliminando parte da subjetividade inerente aos processos de avaliação, uma vez que se considerou o sistema como facilitador no processo de orientação aos profissionais, no que diz respeito a oportunidades de carreira e a priorização de programas de capacitação. O modelo proposto tem, ainda, o diferencial de lidar com categorias distintas de empregados - gestores, técnicos-administrativos e professores - que são regidos e avaliados por diferentes normativas educacionais, além das estratégias organizacionais comuns às empresas privadas.

Palavras-chave: Ensino Superior. Docentes. Modelo de Gestão por Competências. Estratégia. Gestão de Pessoas Estratégica. 


\begin{abstract}
Brazilian Higher Education Institutions (HEIs) are seeking to implement new preventive measures to differentiate themselves from their competitors. A model that stands out in Human Resources Management (HRM) is competency-based management since it has been identified as a model that brings HRM closer to strategic management. This study, therefore, aims to analyze the development and implementation of an HRM model based on competency-based management in a private $\mathrm{HEl}$. This research is a qualitative case study carried out in a private HEI through six interviews and analysis of HEI documents. The results show that the model facilitated the task of managing, enabling more justice and consistency in dealing with people, eliminating part of the subjectivity inherent in the evaluation processes, since the system was considered as a facilitator in the process of guiding professionals, regarding career opportunities and the prioritization of training programs. The proposed model also has the differential of dealing with different categories of employees managers, administrative technicians, and professors - who are governed and evaluated by different educational standards, in addition to the organizational strategies common to private companies.
\end{abstract}

Keywords: Higher Education. Professors. Competency-Based Management Model. Strategic. Strategic Human Resource Management.

\title{
1 INTRODUÇÃO
}

As Instituições de Ensino Superior (IES) brasileiras, frente ao aumento da oferta de cursos de ensino superior à população e ao consequente acirramento da concorrência, estão promovendo transformações na gestão com o objetivo de se destacar no mercado. Em 2019, o censo da educação superior mostrou que existiam 2.608 IES brasileiras, sendo que 2.306 são privadas (INEP, 2020). O alinhamento de políticas e práticas da Gestão de Pessoas (GP) com a estratégia organizacional tem contribuído para qualificar as IES de modo a oferecer serviços de melhor qualidade.

O contexto educacional superior no Brasil é regido por diferentes órgãos e instrumentos, como o Ministério da Educação (MEC), Coordenação de Aperfeiçoamento de Pessoal de Nível Superior (CAPES) e o Exame Nacional de Desempenho de Estudantes (ENADE). Estes avaliam o rendimento das IES por meio do desempenho dos seus docentes e acadêmicos dos cursos de graduação e pós-graduação, seja em relação aos conteúdos programáticos dos cursos, bem como a produção científica e o retorno para a comunidade. Embora, Silva Jr. et al. (2014, p. 216) observem que, em função do número elevado de IES privadas, "as políticas públicas para a educação superior em termos de avaliação, regulação e supervisão envolvem predominantemente as IES privadas", essa relação pode não ser facilmente estabelecida. Isto porque as demandas de ensino, pesquisa e extensão são avaliadas pelos órgãos governamentais com base em IES que tenham uma grande estrutura para prestar um ensino com qualidade e com diversos recursos, o que não é o panorama das IES privadas, que buscam cada vez mais reduzir seus custos e aumentar seus lucros.

Tal conjuntura requer a criação de um modelo de GP que contemple essas demandas, de forma a obterem-se indicadores de desempenho dos profissionais, essenciais à condução das atividades e diretamente ligados à qualidade dos serviços prestados. Por isso, este estudo se justifica sobretudo pelo fato de que grande parcela das IES da rede privada, apesar da 
A implantação de um modelo de gestão de pessoas com base na gestão por competências em uma instituição de ensino superior privada

necessidade de profissionalização, ainda mantém uma postura tradicional de GP (QUEL, 2008).

Assim, os modelos de GP necessitam direcionar as suas políticas para o desenvolvimento das competências dos seus profissionais para que possam ajudá-los a implantar suas estratégias, operar com eficiência, envolver as pessoas e gerenciar mudanças para obter uma vantagem competitiva (LIMA; NORO, 2008). Surge, então, a necessidade de uma gestão por competências como mecanismo para identificar e desenvolver os conhecimentos, habilidades e atitudes necessárias nos docentes e técnicos para a realização de suas atividades de trabalho. Torna-se fundamental, portanto, que as IES definam o perfil e as competências dos seus profissionais a fim de se tornar competitivas.

Lima e Noro (2008) salientam que a gestão por competências permite uma gestão universitária mais eficaz e adequada às necessidades das organizações. Os autores defendem que desenhar procedimentos para a identificação de competências, baseados no papel ativo do sujeito e integrativos de métodos teóricos e empíricos, é a chave para obter descrições de competências dos profissionais, ajustadas aos requerimentos das demandas atuais.

A GP tem alcançado poder de permanência, sendo uma área importante para estudos, uma vez que o seu desafio é preencher as lacunas do conhecimento e abrir novos caminhos de atuação em ambientes dinâmicos e de constante mudança (LENGNICK-HALL et al., 2009). Entretanto, ainda se questiona a importância dessa área no Brasil, bem como o aprofundamento e as contribuições que as pesquisas brasileiras têm emergido (GALLON et al., 2013). O fato é que até mesmo sua legitimidade e permanência no dia a dia organizacional estão cada vez mais condicionadas à comprovação quase matemática de sua efetividade, o que, naturalmente, impõe uma série de desafios (BARBOSA, 2009). De fato, no ambiente corporativo, a GP ainda carece de uma participação mais ativa na gestão e influência estratégica nos negócios das empresas.

A GP, as suas contribuições estratégicas e a elaboração e estruturação de seus processos foram elencadas entre as sete principais lacunas de pesquisas internacionais na área (LENGNICK-HALL et al., 2009). No contexto brasileiro, a elaboração de componentes e estruturas da GP, também foi apontada entre as cinco principais temáticas a serem desenvolvidas (ARMOND et al., 2016). Assim, enfatiza-se a importância de analisar a GP de maneira estratégica, bem como construir um modelo para essa gestão.

Frente ao exposto, há poucos modelos que estruturam a GP. No Brasil, o modelo de GP mais difundido é o de Dutra (2002). A ausência de um modelo de GP que contemple fases e práticas corrobora a dificuldade de se ter um planejamento da área, o que impede a visualização do conhecimento que envolve cada uma de suas práticas. Entender quais práticas estão interligadas é igualmente necessário, para que se possam compreender impactos, implicações e resultados da GP no planejamento estratégico organizacional. Para tanto, o objetivo deste estudo é analisar o desenvolvimento e implantação de um modelo de GP com base na gestão por competências em uma IES privada.

Esta pesquisa se justifica pela abordagem da gestão por competências em uma IES privada, uma vez que os estudos nessa área tendem a privilegiar as IES públicas. Há muitas diferenças entre as IES públicas e privadas brasileiras, visto que as lógicas e dinâmicas vivenciadas por elas são distintas (SILVA Jr. et al., 2014). Embora todas IES se dediquem para o ensino, nem todas buscam desenvolver a pesquisa. Rowe e Bastos (2010) apontam que as IES públicas se dedicam mais à pesquisa do que as IES privadas, corroborando os argumentos de Silva Jr. et al. (2014) de que as IES privadas estão mais próximas do conceito de IES voltada para o ensino, enquanto as IES públicas, estão voltadas para o desenvolvimento da pesquisa. 
Este achado pode estar relacionado ao fato de que as IES privadas com fins lucrativos focam mais suas atividades no ensino (FIORENZE, 2020), enquanto as IES públicas têm mais espaço para desenvolver atividades em programas de pós-graduação. Isto também está relacionado ao fato de que ter professores com dedicação para a pesquisa tem um custo maior, ao passo que as IES privadas não percebem a rentabilização financeira da pesquisa. Neste sentido, o contexto das IES privadas é evidenciado pela sua mercantilização e privatização do ensino (SILVA Jr. et al., 2014; FIORENZE, 2020).

Por tanto, analisar a gestão por competências no contexto docente das IES se torna mais desafiador por ter que conciliar as diferentes perspectivas (governamentais, empresariais e educacionais). Esse contexto se acentua, pois muitas vezes há a cobrança pelo desenvolvimento de algumas atividades (como a pesquisa, em função das normativas governamentais), mas não há o devido respaldo aos profissionais.

Nas próximas seções, será abordada a GP bem como os seus modelos atuais. Em sequência, serão apresentados os procedimentos metodológicos da pesquisa e a análise das informações coletadas. As considerações do estudo compõem a última parte deste.

\section{GESTÃO DE PESSOAS ESTRATÉGICA COM BASE NA GESTÃO POR COMPETÊNCIAS}

Uma empresa que almeja ser líder e se destacar no mercado não pode depender somente de seu êxito econômico, de sua estrutura física e de suas condições materiais, pois, sobretudo, necessita contratar e contar com pessoas qualificadas e geri-las com eficiência (RIBEIRO; MARTINS; NETA, 2017). Para isso, a Gestão de Pessoas (GP) deve ser planejada e estar presente na definição da estratégia empresarial (ULRICH, 2000; ALMEIDA et al., 2013); promover questionamentos para transformar a estratégia em ações; promover políticas e práticas de GP adequadas à estratégia empresarial (ULRICH, 2000); estar integrada com a organização, articulada por meio de sua estratégia, e as necessidades estratégicas da empresa; ter práticas de GP que sejam consistentes política e hierarquicamente; ter práticas ajustadas, aceitas e usadas por gerentes de linha e empregados como parte de seu trabalho diário (SCHULER, 2000); e dispor de ferramentas e métodos para que os empregados tenham tratamento equânime e justo (ROHM; LOPES, 2015).

Coerente a isso, para que a GP contribua para o negócio da empresa, é necessário que suas políticas e práticas atendam às necessidades dos empregados e tenham origem nas demandas estratégicas e não em interesses circunstanciais (DE RÉ; DE RÉ, 2011). No entanto, muitas empresas não desenvolvem um planejamento para a área e têm um comportamento passivo ao reagir às demandas organizacionais (DUTRA, 2014), o que implica em uma contribuição marginal da área para empresa.

Dutra (2014) observa que quando as empresas reagem ao ambiente, ao invés de planejá-lo, acabam desenvolvendo políticas e práticas com premissas muitas vezes conflitantes. Como exemplo, o autor cita o conflito entre políticas de remuneração fixa e variável que acabam incentivando comportamentos opostos. Por isso, a GP deve estar ligada coerentemente à estratégia, pois essa é a única forma de se ter um resultado positivo e contínuo. Assim, quando as estratégias forem alteradas, a GP também será alterada, mantendo uma estrutura intimamente conectada (TANURE; EVANS; PUCIK, 2007).

Esta mudança no posicionamento da GP para um caráter mais estratégico, por meio da adoção de modelos que contemplem não só rotinas administrativas, faz com que o profissional da área tenha que se adaptar, assumindo novas funções e responsabilidades. Isso porque, tradicionalmente, estes profissionais tinham uma atuação que se resumia aos 
A implantação de um modelo de gestão de pessoas com base na gestão por competências em uma instituição de ensino superior privada

subsistemas de GP, tais como recrutamento, seleção e remuneração, com pouca ou nenhuma preocupação de estes estarem articulados aos processos estratégicos (ALMEIDA et al., 2013).

Para isso, a GP deve apresentar uma gestão com resultados, tais como a redução de gastos a fim de conquistar a confiança dos gestores da empresa (ALMEIDA et al., 2013) e, consequentemente, conseguir com que as pessoas da empresa aceitem as mudanças propostas pela GP a fim de ter um papel estratégico. Desta forma, a GP terá o papel de agente de mudança (ULRICH, 2000; ALMEIDA et al., 2013) "ao desenvolver a capacidade da empresa em aceitar a mudança contínua, melhorando incessantemente a concepção e a implantação de iniciativas variadas que garantam seu melhor desempenho" (ALMEIDA et al., 2013, p. 59).

Buscando um modelo de GP que traga um diferencial para a empresa encontra-se a gestão por competências, a qual tem sido apontada como eficiente para as empresas que buscam melhorar o seu desempenho organizacional (MUKHOPADHYAY; SIL, 2011; TRIPATHI; AGRAWAL, 2014) por meio de uma GP estratégica. Este tipo de modelo apoia todos os processos, políticas e práticas de GP - avaliação, desenvolvimento, seleção, carreira e remuneração - no conceito de competências (SILVA, 2003). Deste modo, é atribuição da GP, enquanto parceira estratégica, desenvolver e monitorar as competências na organização (ALMEIDA et al., 2013) para que o modelo seja implementado efetivamente. As vantagens em implantar um modelo com base na gestão por competências estão focadas na facilidade para recompensar de forma justa os empregados, maior flexibilidade da empresa, incentivo ao desenvolvimento pessoal, alinhamento da GP com a estratégia da empresa e com a estratégia de GP e o fortalecimento das lideranças em relação às definições de GP (REJASMUSLERA; URQUIZA; CEPEDA, 2012).

Assim, para iniciar o desenho de um modelo de GP com base na gestão por competências, em um primeiro momento, com base na missão, valores e visão da empresa, deve-se definir as competências essenciais, que são aquelas que diferenciam a organização perante os concorrentes e constituem razão de sua sobrevivência. Elas garantem as vantagens competitivas, são invisíveis, difícil de imitar ou adquirir, pois são resultantes da história da organização e de longo processo de aprendizagem (RUZZARIN; SIMIONOVSCHI, 2010). As competências organizacionais têm caráter dinâmico e não estático. Elas se encontram em constante articulação com a estratégia da empresa, isto é, conforme as estratégias vão sendo definidas, as capacidades vão surgindo, desenvolvendo-se e concretizando-se sob a forma de competências organizacionais (GRANT, 1991).

As competências de nível organizacional são "constituídas a partir da combinação de recursos e de múltiplas competências individuais, de tal forma que o resultado total é maior do que a soma das competências individuais" (FLEURY; FLEURY, 2004, p. 48). Por isso, entende-se que as competências de nível organizacional estão intimamente relacionadas com as competências individuais, uma vez que uma influencia na outra (DUTRA, 2014).

Após a definição das competências essenciais, é preciso definir as especificidades do serviço oferecido para que, a partir de então, sejam traçadas as perspectivas de competências necessárias a cada atividade específica (UBEDA; SANTOS, 2008). Ainda que a gestão por competências "tenha como foco principal a contribuição das pessoas, e também dos grupos, na prática ela ainda se revela vinculada à estrutura de cargos como ponto de partida para sua identificação e posterior desdobramento" (RODRIGUES, 2006, p. 27).

Portanto, a próxima etapa é o mapeamento das competências individuais, como realizado nos estudos de Draganidis e Mentzas (2006), assim como de Mukhopadhyay e Sil (2011). Este mapa de competências mostra os perfis desejados para os cargos, auxiliando na captação de pessoas, necessidades de treinamento e padrões de desempenho (RUZZARIN; 
SIMIONOVSCHI, 2010). Neste modelo proposto, também é importante que as competências definidas possam ser mensuradas para medir os resultados individuais e organizacionais (RODRIGUES, 2006).

A implantação de um modelo de GP com base em competências deve ter início com o envolvimento das lideranças em prol da sua implantação. Dessa forma, compreende-se que após a adesão de pessoas chave da organização, deverá haver também e a sensibilização dos empregados na busca do comprometimento de todos (GRAMIGNA, 2002). Leme (2006) também ressalta a importância deste primeiro momento, afirmando ser necessário apresentar os motivos que justifiquem a implantação dos novos processos na empresa, uma vez que, quando bem estruturada, a venda da ideia fica facilitada (GRAMIGNA, 2002).

A comunicação é outro fator relevante para o sucesso na implantação da gestão por competências, pois o impacto dessa mudança na organização é um fator importante a ser divulgado. Por meio de uma estratégia de comunicação planejada, a empresa pode sinalizar a seus empregados a relevância que a gestão por competências tem para o trabalho e o desenvolvimento da carreira profissional. Ao envolver desta forma, diminui as resistências à mudança e melhora a compreensão quanto aos conceitos das competências por toda a organização (KOCHANSKI, 1997), visto que expressões como competência, fatores críticos de sucesso e características comportamentais não são claros para a maioria dos empregados. Assim, há a necessidade de uma linguagem comum e comunicação efetiva para os empregados para o sucesso da implantação (GANGANI; MCLEAN; BRADEN, 2006).

Em um processo de mudança organizacional, a resistência das pessoas pode ser prejudicial (MARQUES; BORGES; REIS, 2016) para a implantação do novo modelo. Um dos motivos para a resistência é quando o indivíduo não tem certeza em relação às vantagens da mudança, assim, ele acaba se tornando resistente (MARQUES et al., 2014). Outro motivo também que faz com que a pessoa acredite que está sendo afetada negativamente pela mudança é a pressão do grupo e a exigência que os empregados alterem hábitos antigos (MARQUES et al., 2014). Estas resistências normalmente são fruto da falta de comunicação por parte organização em informar qual é a mudança, como e por que está sendo feita, sem explicitar as expectativas (MARQUES; BORGES; REIS, 2016).

Após os devidos esclarecimentos, deve ser realizada uma avaliação interna da organização. De acordo com Gramigna (2002), no momento da avaliação de desempenho, identifica-se o perfil requerido de competências de acordo com as necessidades e estratégia da empresa. Esta avaliação pode ser feita com base na prontidão do cargo que, conforme Ruzzarin e Simionovschi (2010), a prontidão do cargo refere-se ao processo continuado de crescimento e aquisição das competências requeridas significa avaliar e concluir o quanto a pessoa ocupante do cargo está apta para os desafios. Os autores definem o conceito de prontidão como um olhar para o futuro, ou seja, o quanto a pessoa já adquiriu das competências requeridas e quais seriam os caminhos a serem traçados.

O papel do líder na condução do feedback é importante neste processo para que a devolutiva atinja o objetivo de desenvolvimento do empregado (RUZZARIN; SIMIONOVSCHI, 2010). Para tanto, a avaliação de desempenho deve ter como foco o crescimento pessoal do empregado e não deve ser usada com propósitos administrativos (como promoções ou demissões) (BRANDÃO et al., 2008).

Para implementar um modelo de GP com base na gestão por competências é necessária uma mudança de pensamento das organizações. A mudança da GP tradicional, com base nos modelos tayloristas e fordistas, para um modelo com base na gestão por competências está baseada no deslocamento do foco da GP do controle para o 
A implantação de um modelo de gestão de pessoas com base na gestão por competências em uma instituição de ensino superior privada

desenvolvimento (DUTRA, 2014). No modelo tradicional, as pessoas são percebidas como "objetos de controle e, portanto, espera-se delas uma postura passiva" (DUTRA, 2014, p. 19). Nesta perspectiva de GP, há uma expectativa de que as políticas e práticas sejam desenvolvidas visando um desenvolvimento mútuo: "de um lado, a empresa, ao desenvolverse, desenvolve as pessoas; de outro, as pessoas, ao desenvolverem-se, desenvolvem a empresa" (DUTRA, 2014, p. 19).

Isso possibilita que o empregado vislumbre "um horizonte mais amplo do que o cargo que ocupa na sua relação com a empresa, ao mesmo tempo em que o horizonte fica mais claro tanto para a pessoa quanto para a empresa" (DUTRA, 2014, p. 65), conciliando as expectativas dele com as da empresa (DUTRA, 2014). Este contexto possibilita mostrar "com nitidez o papel da pessoa na gestão de seu desenvolvimento e de sua carreira e o papel da empresa no suporte ao desenvolvimento da pessoa" (DUTRA, 2014, p. 65).

A noção de competência abandona o olhar a partir de um perfil ao qual deve-se enquadrar-se e passa a analisar os empregados na perspectiva de sua entrega (DUTRA, 2014). Esta nova concepção entende que "se uma pessoa agrega valor à medida que assume responsabilidades e atribuições mais complexas, não é necessário promovê-la para que possa agregar valor. A pessoa pode ampliar o nível de complexidade de suas atribuições e responsabilidades sem mudar de cargo ou posição na empresa" (DUTRA, 2014, p. 51).

Este novo modelo vem em contraposição aos modelos clássicos que focam na qualificação do empregado, mais enfaticamente, na valorização dos diplomas (ZARIFIAN, 2002). Assim, a gestão por competências emerge ao valorizar a trajetória da pessoa, contraponto os atuais processos de GP baseados na descrição de cargos, tarefas ou uma profissão (ZARIFIAN, 2002; DUTRA, 2014).

Com o reconhecimento da contribuição estratégica que a gestão por competências pode trazer à organização houve a popularização e o uso em demasia do conceito de competências nas empresas, emergindo um novo modismo da GP. Este modismo da gestão de competências tem sido atrelado aos modelos prontos disponibilizados por consultorias os chamados pacotes - que tentam implementá-los de qualquer maneira (DUTRA, 2014) sem levar em consideração o contexto, a estratégia, o negócio e as competências de cada empresa.

O modismo da gestão por competências é agravado quando o uso do conceito de competências é feito de maneira rasa sem o seu entendimento mais profundo e consistente (DUTRA, 2014). Assim, as empresas que utilizam este conceito de maneira simples acabam não tendo os resultados esperados e restringem a gestão por competência para processos pontuais, como recrutamento e seleção (DUTRA, 2014). Isso implica em uma marginalização da gestão por competências com políticas e práticas de GP deslocadas da estratégia organizacional perpetuando um modelo atualizado da GP tradicional (ZARIFIAN, 2002). No entanto, "o conceito de competência, quando compreendido em toda a sua extensão e utilizado em conjunto com outros conceitos, permite grande avanço na compreensão da GP na empresa moderna" (DUTRA, 2014, p. 16).

\section{PROCEDIMENTOS METODOLÓGICOS}

A presente pesquisa é um estudo de caso (YIN, 2010) descritivo de abordagem qualitativa realizado em uma IES privada denominada de maneira fictícia de 'Faculdade Brasil'. A IES foi escolhida devido ao seu recente processo de reestruturação de GP, buscando consolidar um modelo que contribua para o desenvolvimento do seu planejamento estratégico.

RGO - Revista Gestão Organizacional, Chapecó, v. 14, n. 2, p. 69-94, maio/ago. 2021. 
A coleta de dados foi realizada por meio de entrevistas, com base em um roteiro semiestruturado. O roteiro foi desenvolvido com base no referencial teórico exposto (GRAMIGNA, 2002; GANGANI; MCLEAN; BRADEN, 2006; LEME, 2006; RODRIGUES, 2006; RUZZARIN; SIMIONOVSCHI, 2010), contendo 10 perguntas que abordavam a necessidade do modelo, o desenvolvimento do modelo, a participação do entrevistado na implantação do modelo e dificuldades e facilidades da implantação do modelo. Para tanto, foram entrevistadas seis pessoas que fizeram parte do comitê de estruturação das políticas de GP, sendo elas pertencentes a diferentes grupos em relação aos cargos, setores, sexo, idade, formação e tempo de casa (Quadro 1).

Quadro 1 - Perfil dos entrevistados

\begin{tabular}{|c|c|c|c|}
\hline Entrevistado (a) & Grau de Instrução & Cargo & $\begin{array}{c}\text { Tempo } \\
\text { na IES }\end{array}$ \\
\hline E1 & Mestrado (em andamento) em Administração & $\begin{array}{c}\text { Coordenadora de } \\
\text { Gestão de Pessoas }\end{array}$ & 8 anos \\
\hline E2 & Mestrado (em andamento) em Administração & Diretora Administrativa & 9 anos \\
\hline E3 & Doutorado em Psicologia Clínica & Coordenador de Curso & 9 anos \\
\hline E4 & Mestrado (em andamento) em Administração & Gerente de Negócios & 6 anos \\
\hline E5 & Doutorado (em andamento) em Odontologia & Coordenador de Curso & 1 ano \\
\hline E6 & Doutorado (em andamento) em Administração & $\begin{array}{c}\text { Diretor de Relações } \\
\text { com o Mercado }\end{array}$ & 8 anos \\
\hline E7 & Doutorado em Educação & Coordenador de Curso & 9 anos \\
\hline
\end{tabular}

Fonte: elaborado pelas autoras (2020) com base nas informações da pesquisa.

As entrevistas foram gravadas, mediante a autorização dos participantes e, posteriormente, transcritas e analisadas por meio da técnica de análise de conteúdo (BARDIN, 2009). Conforme o trabalho de categorização era desenvolvido, as categorias primárias foram surgindo naturalmente. Durante e no final do processo de categorização, era realizada nova organização das categorias, caracterizando um processo contínuo (Quadro 2).

Quadro 2 - Categorização da análise de dados

\begin{tabular}{|c|c|c|}
\hline Categoria inicial & Categoria Intermediária & Categoria Final \\
\hline O Contexto da IES & \multirow[b]{2}{*}{ A Faculdade Brasil } & \multirow{12}{*}{$\begin{array}{l}\text { A implantação de um modelo de GP } \\
\text { com base na gestão por } \\
\text { competências em uma IES privada }\end{array}$} \\
\hline GP Estratégica & & \\
\hline Necessidade do modelo & \multirow{4}{*}{ O Modelo de GP } & \\
\hline O comitê & & \\
\hline Construção do modelo & & \\
\hline O modelo & & \\
\hline A implantação & \multirow{4}{*}{ Implantação do modelo } & \\
\hline As mudanças na IES & & \\
\hline Facilidades & & \\
\hline Dificuldades & & \\
\hline Modelo atualmente & \multirow{2}{*}{ O modelo e seus desafios } & \\
\hline Desafios do modelo & & \\
\hline
\end{tabular}

Fonte: elaborado pelas autoras (2020) com base nas informações da pesquisa.

Também houve uma pesquisa documental realizada em reportagens e documentos disponibilizados pela própria IES, tais como o manual de Gestão de Pessoas, a cartilha que foi entregue aos empregados com a descrição do modelo e o site da IES em que continha informações sobre o planejamento estratégico (2016-2020). Foram analisadas as políticas de GP, fases de implantação do modelo e missão, visão e valores da IES. Essas informações foram fundamentais à compreensão do modelo, ao desenvolvimento do roteiro de entrevista, à contextualização da IES e à análise dos dados coletados. 
A implantação de um modelo de gestão de pessoas com base na gestão por competências em uma instituição de ensino superior privada

\section{ANÁLISE DOS RESULTADOS: A IMPLANTAÇÃO DE UM MODELO DE GESTÃO DE PESSOAS}

A análise dos resultados está na baseada nas categorias intermediárias. A categoria 'a Faculdade Brasil' aborda o contexto da IES e GP estratégica; a categoria 'o modelo de GP' analisa a necessidade do modelo, o comitê, construção do modelo e o modelo; a categoria 'implantação do modelo' retrata a implantação, as mudanças na IES, facilidades e dificuldades; e, por fim, a categoria 'o modelo e seus desafios' aborda o modelo atualmente e desafios do modelo.

\subsection{A FACULDADE BRASIL}

A Faculdade Brasil é uma sociedade anônima de capital fechado, com campi em duas cidades brasileiras. Ela presta serviços nas áreas de graduação, pós-graduação, educação executiva e consultoria, contando com mais de 350 profissionais (entre técnicoadministrativos e docentes) e mais de 5 mil alunos (graduação, pós-graduação lato sensu, mestrado acadêmico e doutorado acadêmico interinstitucional).

Apesar de sua curta história (fundada em 2005), a "Faculdade Brasil cresceu absurdamente" (E7) nos últimos anos e é descrita como "uma empresa muito dinâmica" (E4), muito em função de ter "uma galera muito jovem" (E4) na equipe de trabalho. O dinamismo da IES também ocorre por ser uma empresa privada, com um planejamento estruturado e com um conselho societário presente no desenvolvimento dos direcionamentos da IES.

\subsection{O MODELO DE GESTÃO DE PESSOAS}

Frente a esse contexto, em 2008 surgiu a necessidade de um modelo de GP, pois a IES "ainda estava numa fase de crescimento, mas um crescimento desordenado porque tinha muita oportunidade, mas não tinha suporte. A parte administrativa como a parte acadêmica precisava de uma estruturação tanto em nível de sociedade, como em nível de processo" (E2).

Na percepção do E2, a partir desse crescimento:

A gente precisava de formação de mão de obra e de lideranças para assumir
determinadas vagas que começaram a surgir devido a esse crescimento e, para isso,
a gente se deu conta que precisava preparar toda uma base. Nós não tínhamos
nenhum procedimento escrito e também não comunicávamos, fazia o processo na
medida que ia aparecendo o problema e a gente resolvia, e a gente viu que com o
processo de crescimento não íamos conseguir operar com essa estratégia.

A primeira mudança realizada foi com o sistema de informação de gestão, pois "não atendia a expectativa da Faculdade Brasil em relação à rapidez das informações, segurança" (E2). Com isso, a IES passou a desenvolver todas as atividades de gestão dentro da empresa "porque parte das atividades eram terceirizadas, por exemplo, contabilidade e GP. Então, com a troca de sistema, a gente colocou tudo para dentro. A partir dessa opção que a Faculdade Brasil faz, a gente passa ter todos os serviços aqui dentro" (E2).

A necessidade do modelo emergiu em função de "descrever os procedimentos de como deve ser realizado e aí, com isso, você o torna transparente para melhorar esse convívio entre o que precisa ser feito e o que era feito" (E2), pois "a Faculdade Brasil era muito aberta, cada um dava seu jeitinho e cada gestor levava de um jeito" (E4). Nesse contexto, o modelo surge para amenizar "as diferenças e interesses de cada um" (E5) visto que "alguns dos nossos professores são sócios da instituição e aí a gente tem um viés diferente dentro da equipe que, muitas vezes, ressalta em reuniões" (E5). Assim, trabalhar "com essas diferenças e interesses 
de cada um é um desafio e se nós não estivermos preparados para isso, não tivermos ferramentas para isso, fica mais difícil ainda" (E5).

$\mathrm{Na}$ GP, o crescimento da IES impactou em "uma defasagem entre os cargos, as características, as competências necessárias. Naquela época tinha uma diferença gritante na questão salarial, que é um dos pontos que a gente tinha mais impacto e não tinha uma clareza dos benefícios" (E6). Frente a esse contexto, emerge a necessidade do modelo de GP que assegure que os empregados tenham tratamento equânime e justo (ROHM; LOPES, 2015). Para isso, a Faculdade Brasil precisava definir procedimentos básicos para dar este tratamento igualitário para todos os empregados, como relata a E1:

\begin{abstract}
A gente precisa definir como que promove, como que contrata, que dia que contrata, se eu tenho mais de um ano de casa, eu posso concorrer alguma vaga. Então, assim, são várias políticas que a gente não tinha nada escrito, então, quando a gente não tem nada definido, acaba que eu tenho tratamentos diferenciados, então, para ti eu vou fazer de um jeito para o outro eu vou fazer de outro, então, não se tem um nivelamento, em termos de normativa.
\end{abstract}

Com isso, "as políticas vieram para reforçar práticas que a gente já fazia, mas não tinha uma formalização" (E4). A implantação das práticas de GP iniciou-se em 2011 por meio da gestão por competências para os empregados técnico-administrativos. Porém, "no decorrer dos ciclos de avaliação, mesmo com algumas melhorias, percebeu-se que o modelo adotado não estava atendendo as necessidades da IES" (E1). Essa prática, entretanto, foi usada até o ano de 2013, permitindo que fossem mapeados os cargos existentes e revisto o organograma e a descrição dos cargos e salários destes profissionais.

Assim, sentiu-se a necessidade de se ter um modelo integrado que contemplasse o profissional como um todo, atendesse o aumento do quadro profissional, envolvesse a gestão da IES e fosse aplicado de forma sistêmica e coerente com os pressupostos do modelo (SILVA, 2003; DUTRA, 2014). Isso implicou no "desenvolvimento de um modelo, até então, inovador em IES deste porte, devido à inclusão do quadro docente na gestão por competências" (E1). Houve, assim, a mudança para um modelo de GP com base na gestão por competências de todos os seus empregados.

Um dos primeiros passos foi mapear as competências essenciais - aquelas que diferenciam a organização perante os concorrentes (RUZZARIN; SIMIONOVSCHI, 2010) -, sendo a base norteadora dos profissionais da Faculdade Brasil. Esse mapeamento foi realizado pela direção e pelos responsáveis pela GP, com base na missão, visão, valores e planejamento estratégico da IES, resultando em três competências essenciais: foco em resultados e qualidade; empreendedorismo; e cooperação.

Em seguida, o conselho de sócios desenvolveu um esboço de diretrizes "do que se queira para essas políticas, mas houve muito dos gestores da época, em dar os contornos de como se desenharia isso" (E6). Assim, "nós optamos em desenvolver as políticas de GP e contratamos uma consultoria" (E1), a qual "conduziu todo o processo e alguns gestores aqui na Faculdade Brasil foram convidados a participar" (E4). A fim de evitar de trazer um modelo pronto (DUTRA, 2014), o comitê tinha o intuito de "trazer ideias de fora, de coisas que, já tinha conhecimento, já tinha experimentado, já tinha vivido pra poder contribuir" (E4), formado por "nove pessoas e tinha diretores, coordenadores de curso, diretores administrativos e GP. Então, era esses quatro grupos e tinha nove pessoas das mais variadas áreas" (E1).

Para o desenvolvimento das políticas, "a consultora já trazia uma ideia e em cima daquelas ideias a gente ia debatendo e construindo, foi uma experiência bem bacana" (E4). Em relação às discordâncias no comitê, "quando surgia um conflito na discussão do grupo, a 
A implantação de um modelo de gestão de pessoas com base na gestão por competências em uma instituição de ensino superior privada

gente formulava as propostas e identificava os conflitos pra depois chegar ao consenso do que a Faculdade Brasil queria" (E2). Dessa maneira, "tinha um espaço fértil pra ti inovar, criar, implantar" (E2). Mesmo que a gestão das IES privadas com fins lucrativos seja realizada por "profissionais desvinculados do corpo acadêmico, seguindo um padrão empresarial e centralizado" (FIOREZE, 2020, p. 83), na Faculdade Brasil, o modelo de GP foi desenvolvido com base em diferentes perspectivas de empregados (professores, técnicos administrativos, gestores e consultores).

Para a construção do modelo, foi definido um esboço pensando já no futuro, pois "mesmo que tivesse um número grande de políticas e elas fossem começando a ser implementadas, elas poderiam ser fragmentadas. Mesmo assim sabia todo o quadro que se queria" (E6). A construção começou pelas políticas, por "exemplo: política de seleção e recrutamento, como tem que ser? Como eu quero ou como tem que ser?" (E2). De acordo com os entrevistados, todas as políticas foram discutidas e trabalhadas, principalmente, em função de ter que entender o conceito de gestão por competências, como relata o E3:

\begin{abstract}
Isso gerou muitas discussões, muitos debates, até certos pontos algumas incompreensões e depois na efetivação da política, da proposta, a gente conseguiu limpar um pouco mais. Enfim, era pra entender a filosofia da proposta, o que significa uma determinada competência, o que significa outra competência. O conceito de empreendedorismo foi muito falado, o que se entende, cada um dizia uma coisa, até chegar numa compreensão, num ponto de vista mais teórico, para buscar a aplicabilidade das políticas.
\end{abstract}

Durante uma etapa da construção, "a consultoria fez alguns encontros conosco explicando a metodologia, como funcionava, nós fizemos um esforço para entender o perfil do docente e do gestor, que são carreiras diferentes, teve um processo de construção e depois foi para as políticas" (E7). Assim, os entrevistados relatam que durante o processo de construção do modelo a "consultora veio com um esboço, digamos assim, de tópicos que nós tínhamos que definir, pra fazer uma leitura prévia, nós fizemos essa leitura das políticas e nós fizemos quatro encontros de oito horas para ler política por política" (E1). Para tanto, "a gente ia lendo os textos 'ah esse texto não se encaixa com a Faculdade Brasil', 'ah isso, é assim que a gente quer que seja'. Então, foi assim que a gente iniciou e chegou até elas, as políticas" (E1).

\title{
4.3 IMPLANTAÇÃO DO MODELO
}

Mesmo assim, no decorrer da implantação do modelo, algumas políticas foram alteradas, "porque a gente viu que muitas coisas que funcionam numa empresa, nem sempre vão funcionar em outras" (E4). Exemplo disso, foi uma política que "eles tinham que esperar seis meses para uma próxima vaga. Depois, a gente derrubou essa política porque ela não servia para a Faculdade Brasil" (E4).

Foi a partir destes encontros que "a gente estruturou 12 políticas da Faculdade Brasil" (E6), as quais estão formalizadas no "caderno Faculdade Brasil de Gestão de Pessoas" que "é um livro em que estão descritas todas essas políticas, os procedimentos e como deve ser realizado" (E2). Este caderno é entregue para os empregados quando ingressam na IES com o intuito de institucionalizar e padronizar as políticas de GP (Figura 1) de acordo com objetivos, premissas, responsabilidades e procedimentos pertinentes a cada uma. 
Figura 1 - Políticas de Gestão de Pessoas da Faculdade Brasil

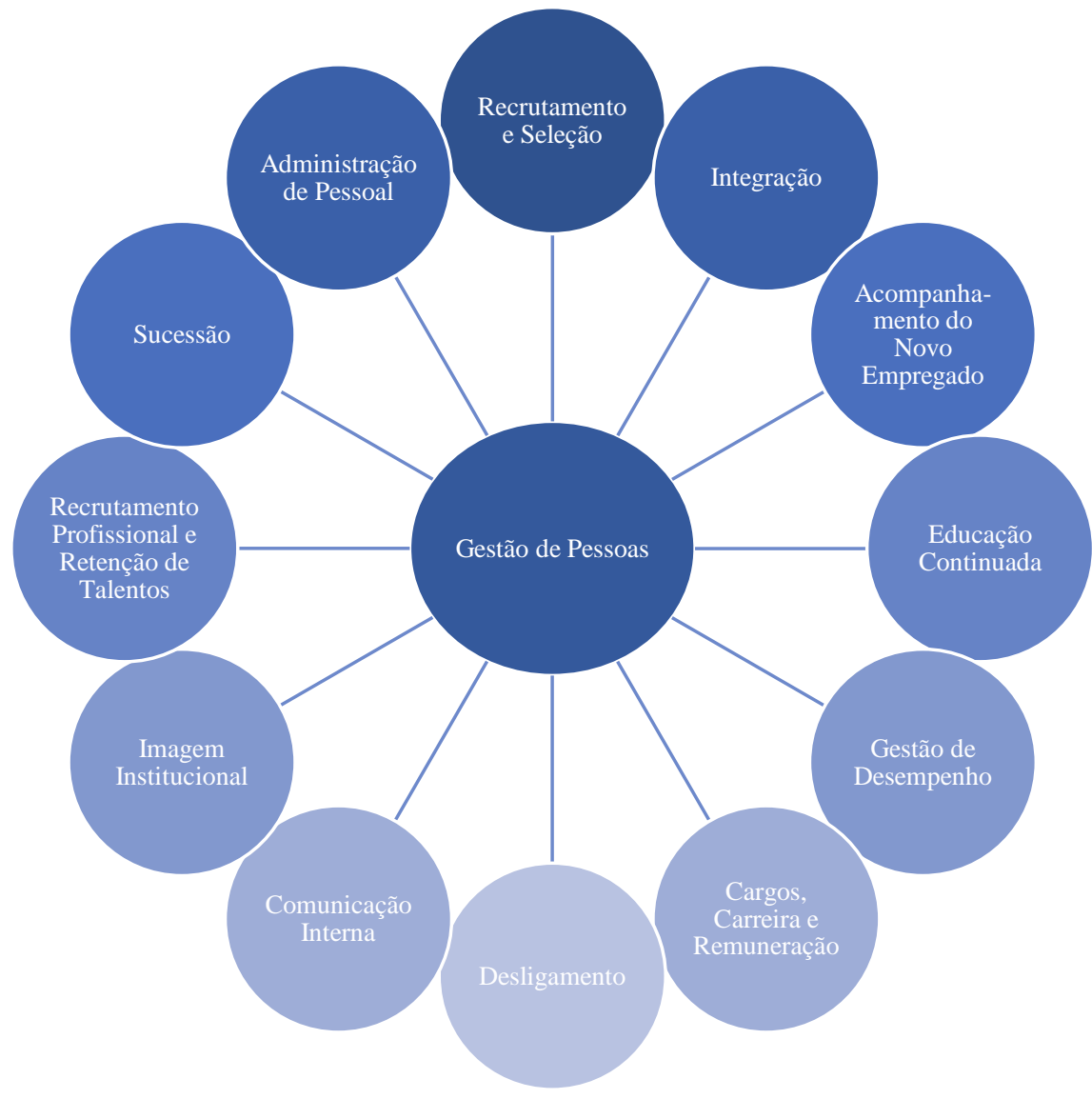

Fonte: Faculdade Brasil (2020).

A divulgação das 12 políticas foi feita "para os gestores e eles ficaram de comunicar para equipe" (E1). Logo após a divulgação, "nós não implantamos todas elas ao mesmo tempo e isso foi bem importante porque não tem como implantar todas elas ao mesmo tempo" (E2). A IES demorou em torno de quatro anos para todas elas fossem implantadas, por causa do "impacto financeiro. A gente foi com calma, para ir incorporando esses custos para dentro da gestão orçamentária" (E2). Quando as políticas começaram a ser aplicadas, "a instituição não tinha estrutura nem de GP e nem financeira pra implementar tudo conjuntamente, então se fracionou e foi uma coisa muita bacana e que a gente deu conta" (E6). Para essas implantações, foi organizado um calendário, como relata E1:

\footnotetext{
Teve um cronograma de implantação e a última política ficou para 2016 [...] porque tem políticas que são muito densas né, exemplo política de cargos, carreira e remuneração, então redefinir cargos, salários, carreira, os eixos e colocar em prática né, porque uma coisa é escrever e outra é colocar em prática, roda as avaliações, ver quem tá apto para promoções, então tudo isso foi feito e elas tão rodando agora.
}

As 12 políticas elaboradas foram organizadas dentro de sete subsistemas de GP (Figura 2). A cada subsistema implantado, surgiu a necessidade de se rever as políticas, processos e procedimentos institucionalizados para que eles convergissem entre si (TANURE; EVANS; PUCIK, 2007), a fim de atender a estratégia empresarial, corroborando a perspectiva estratégica da área apontada por Richey e Wally (1998), Schuler (2000), Dutra (2002), Tanure, Evans e Pucik (2007) e De Ré e De Ré (2011). 
A implantação de um modelo de gestão de pessoas com base na gestão por competências em uma instituição de ensino superior privada

Figura 2 - Gestão de Pessoas da Faculdade Brasil

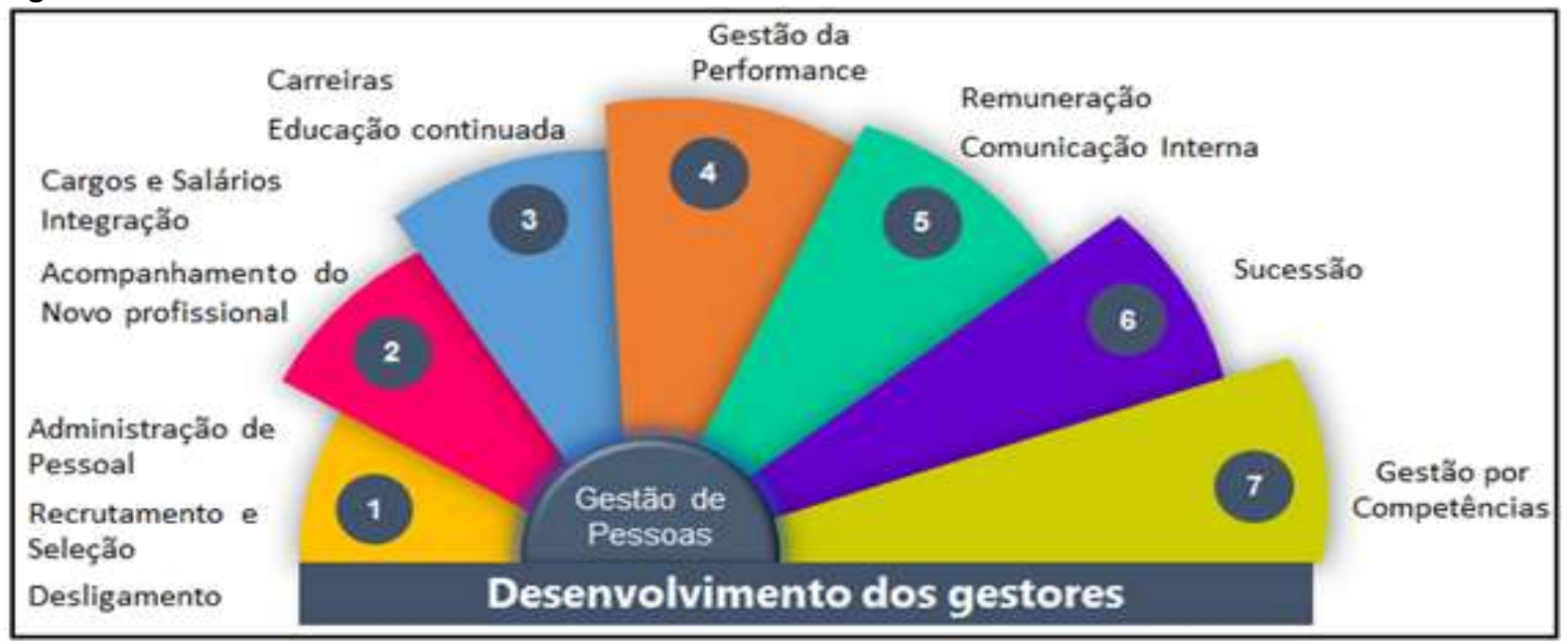

Fonte: Faculdade Brasil (2020).

O modelo integrado de GP com base em competências é um instrumento gerencial de acompanhamento e direcionamento de carreira, em que são conciliados o desenvolvimento profissional e as necessidades da empresa. Ele traça o mapa de competências desejado para os cargos da IES, auxiliando na captação de pessoas, necessidades de treinamento e padrões de desempenho (RUZZARIN; SIMIONOVSCHI, 2010). Desta forma, a IES se volta ao modelo GP de maneira integrada a fim de conectar os processos de GP (Figura 3).

Figura 3 - Processos de Gestão de Pessoas

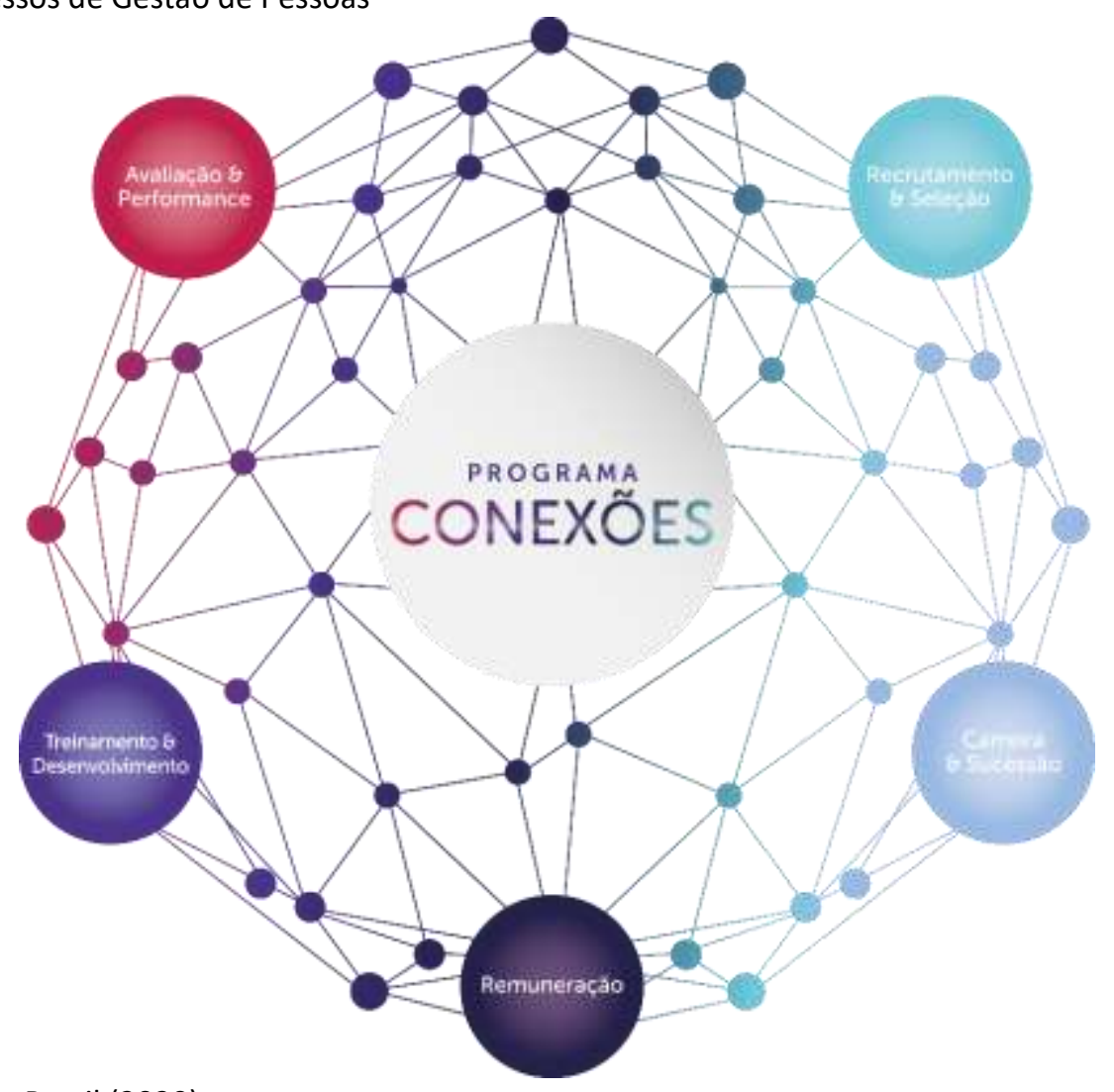

Fonte: Faculdade Brasil (2020).

Em 2014, iniciou-se a implantação da gestão por competências, institucionalizado como o 'programa conexões: ligando você a novas possibilidades'. Este programa tem como principal objetivo ser a base do modelo de GP para identificar, gerenciar e desenvolver de 
forma diferenciada os profissionais da Faculdade Brasil, impulsionando o máximo potencial, principalmente do quadro docente, e garantir a qualidade do ensino oferecido pela IES. Entre suas premissas, busca oferecer uma gestão compartilhada, para que os líderes tenham mais autonomia para gerir suas equipes dentro de um modelo baseado em competências, mediante constante feedback e na importância de desenvolver as pessoas para o alcance dos resultados. Tal intuito corrobora a percepção de Lima e Noro (2008) ao salientarem que a gestão por competências permite uma gestão universitária mais eficaz e adequada às necessidades das organizações proporcionando um desenvolvimento mútuo - da empresa e dos empregados (DUTRA, 2014, p. 19).

O programa atua como um guia para o crescimento e para a movimentação vertical e horizontal da carreira dos profissionais, além de tornar transparente e clara a estrutura de cargos e carreiras da Faculdade Brasil, fazendo com que os profissionais se sintam estimulados a crescer, visualizando as oportunidades de crescimento e desenvolvimento. Visa, também, definir regras para a gestão da carreira, possibilitando o mapeamento e desenvolvimento de potenciais talentos preparados para o crescimento da IES. Assim, o programa mostra-se coerente com os pressupostos da gestão por competências em valorizar a trajetória da pessoa e não somente a descrição de cargos (ZARIFIAN, 2002; DUTRA, 2014).

Para cada cargo, foi elaborado o mapa de competências, que é considerado a "espinha dorsal" (E1) do modelo de GP da Faculdade Brasil e serve como guia para desenvolvimento de cada profissional. Nesse mapa, apresentam-se as responsabilidades (entregas do cargo), competências técnicas e comportamentais, bem como os requisitos de acesso e formação. 0 mapa de competências foi construído em conjunto com as lideranças das áreas, sendo fator decisivo para o engajamento em termos de carreira (GRAMIGNA, 2002).

Para ser promovido, cada profissional deverá desenvolver-se no cargo que ocupa por meio do mapa de competências. Para isso, cada um irá identificar qual plano de carreira da Faculdade Brasil quer percorrer. Após identificá-la, deverá preparar-se para isso, sendo papel da IES estimular o desenvolvimento e a realização profissional dos interessados. É importante mencionar que o plano de carreira permite ao profissional um crescimento natural em seu setor de trabalho e nas demais carreiras existentes na IES, possibilitando, desta forma, uma mobilidade e aproveitamento interno de talentos.

Para isso, foi estruturada a hierarquia dos cargos para que todos possam conhecer os níveis existentes e o que deve ser feito para planejar sua trajetória de carreira (Figura 4). Esta estrutura está organizada conforme os grupos de cargos existentes - distribuídos em níveis hierárquicos (estratégico, tático e operacional) de atuação - com base no modelo de carreira $Y$, pois possibilita o profissional transitar de forma mais flexível por funções técnicas ou gerenciais. 
A implantação de um modelo de gestão de pessoas com base na gestão por competências em uma instituição de ensino superior privada

Figura 4 - Estrutura de Cargos em Y

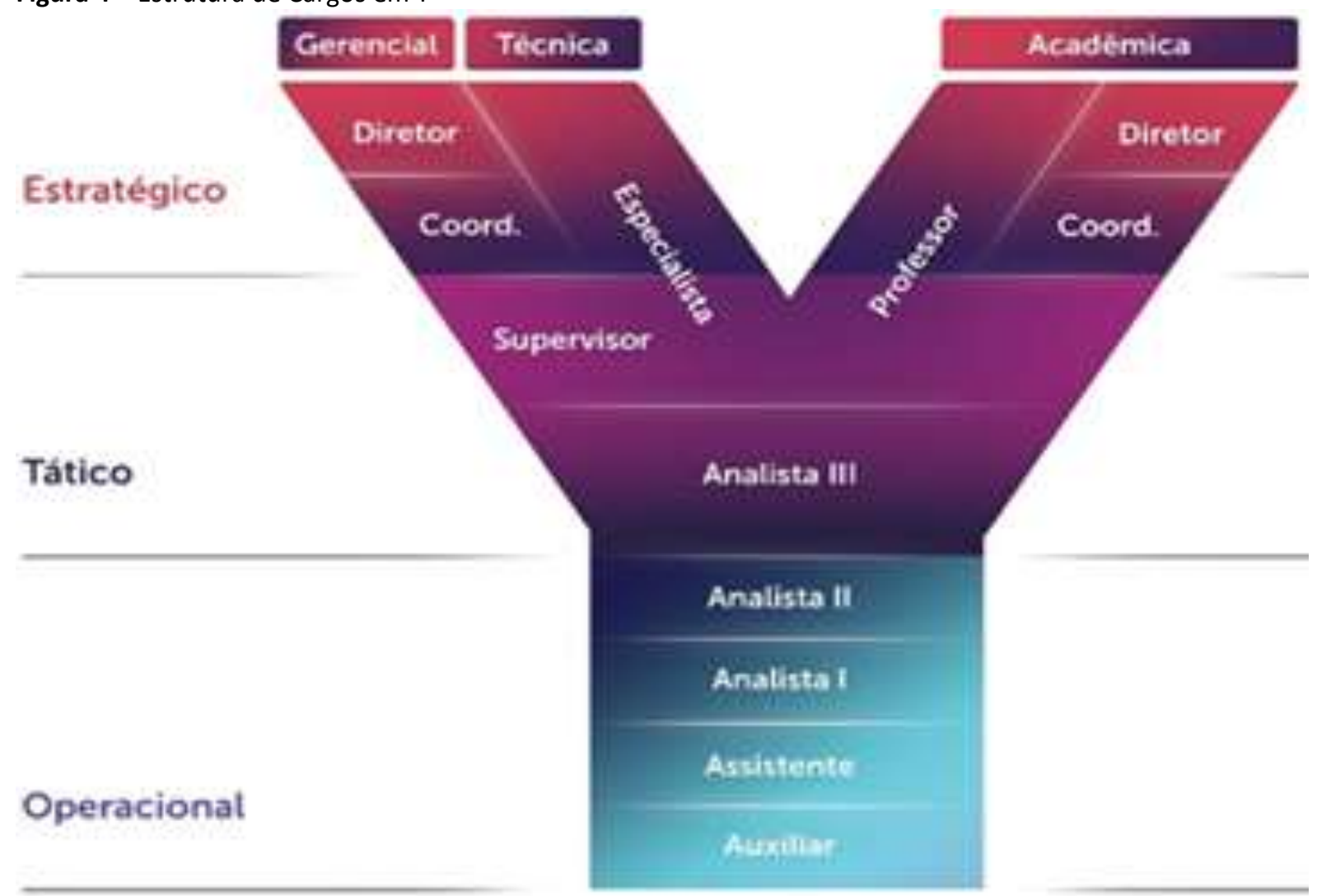

Fonte: Faculdade Brasil (2020).

O recrutamento e seleção ocorre por meio da comparação do mapa de competências com o potencial e maturidade dos candidatos. Este procedimento sinaliza ao gestor da vaga se o candidato está próximo do perfil que a Faculdade Brasil está buscando, fundamentado com critérios justos e claros, minimizando a subjetividade. Também objetiva selecionar, tanto na área acadêmica quanto técnico-administrativa, profissionais que se identifiquem com os valores da IES, bem como com desempenho técnico e comportamental coerente com os objetivos estratégicos da empresa.

O processo de treinamento e desenvolvimento baseia-se nas competências das pessoas no exercício dos seus cargos e, portanto, deve abastecer-se nos desdobramentos do processo de avaliação de competências. Assim, esse processo visa oportunizar o desenvolvimento da educação corporativa voltada à disponibilização e construção de conhecimentos de interesse da IES, no qual os profissionais recebem capacitação e qualificação profissional permanentes.

Para tanto, o processo de treinamento e desenvolvimento desenvolve os docentes para que sejam referência em educação e os profissionais do quadro técnico-administrativo forneçam suporte de qualidade para todos os públicos, a fim de que a Faculdade Brasil alcance a excelência desejada. Já os gestores devem ser desenvolvidos contemplando políticas de GP, negócio, marketing, órgãos reguladores, empreendedorismo e outras áreas da IES. Esse processo deve criar formas de gerir o conhecimento, transformando as estruturas da empresa em um sistema organizacional que aprende.

O processo de remuneração reforça os valores, crenças e comportamentos que estejam alinhados ao planejamento estratégico da IES a fim de atrair e reter talentos. A Faculdade Brasil acredita em uma remuneração justa, o que inclui, além do salário fixo, benefícios atrativos, programa de participação nos resultados, função gratificada e 
remuneração variável. Os padrões de remuneração são compatíveis com as atribuições do cargo, desempenho, capacidade financeira da IES e disposições legais. Além disso, busca valorizar o profissional, oferecendo-Ihe oportunidades de crescimento, tanto vertical como horizontal.

A antiga prática de gestão de desempenho focava somente os profissionais técnicoadministrativos e se baseava no desempenho realizado no período do cronograma proposto, deixando uma lacuna a respeito do desenvolvimento contínuo dos profissionais. Com a implantação do programa conexões, as avaliações passaram a ser baseadas nas competências que estão descritas no mapa de cada cargo e, consequentemente, a avaliação do desempenho contrapõe as responsabilidades definidas e as competências colocadas em prática a fim de identificar a entrega/resultado do empregado.

O programa conexões está baseado em competências de prontidão do cargo (RUZZARIN; SIMIONOVSCHI, 2010), ou seja, a finalidade do processo de avaliação é o desenvolvimento das competências dos profissionais. Assim, a avaliação das competências da Faculdade Brasil segue o princípio de quatro quadrantes, associados à maturidade das competências: desenvolvimento, aplicação, otimização e excelência.

O nível de desenvolvimento é assinalado para profissionais que estão em fase de integração no cargo e de aprendizagem das tarefas. O nível de otimização mostra que as atividades do cargo estão superando os padrões esperados de entrega, sendo capaz de solucionar questões complexas da atividade. O nível de excelência é para as pessoas cujos critérios de avaliação são considerados como parâmetros de referência e o seu trabalho foca em atividades de criação, inovação, treinamento, orientação e/ou liderança de equipes, sendo capaz de solucionar questões de grande complexidade da atividade. Na avaliação, conforme ressaltado por Gramigna (2002), é possível traçar um caminho de desenvolvimento abrangendo as lacunas que precisam ser desenvolvidas por meio de um Plano de Desenvolvimento Individual (PDI). Este é uma importante ferramenta na gestão por competências para que o empregado assuma a gestão da sua carreira evitando um comportamento passivo do seu desenvolvimento.

Para que o modelo integrado de GP possa ser efetivo e gerar um valor real à IES, fazse necessária a realização de alguns rituais de governança por parte da GP e da direção da área envolvida. Um desses rituais é a calibragem e verificação da qualidade das avaliações realizadas pelas lideranças capacitadas neste processo. A calibragem visa fundamentalmente checar se todos os fatores foram avaliados, se o avaliador entendeu os critérios e conceitos do modelo, de forma que o mesmo possa ser internalizado na íntegra conforme proposto pela IES. Sempre orientado por uma postura construtiva e educadora, cabe à GP e à direção da área orientar o líder a refazer as suas avaliações, caso estejam desalinhadas com o método, para que os princípios de equidade e justiça sejam preservados no programa conexões.

Para a realização da avaliação de consenso e feedback é necessário que o gestor levante dados, fatos e evidências que serão utilizados na devolutiva com o profissional avaliado. Ao fornecer o feedback para seus liderados, salienta-se a importância de obter informações de determinados comportamentos e desempenho, para que leve o profissional a tomar consciência que seu desempenho atingiu o padrão desejado ou ficou abaixo das expectativas. Assim, é importante registrar, tanto os momentos de dificuldades (oportunidades de melhorias), como os momentos de superação (elogios).

Para que este processo seja realizado de forma consensual, o gestor deve estimular que o profissional relate suas percepções acerca de sua avaliação e colabore com evidências que vem ao encontro da avaliação ou contrapontos. Neste caso, é necessário rever o resultado 
A implantação de um modelo de gestão de pessoas com base na gestão por competências em uma instituição de ensino superior privada

da competência juntamente com o avaliado, focando o crescimento pessoal do empregado (BRANDÃO et al., 2008). O papel da liderança na condução do feedback é fundamental, pois é por meio da devolutiva que essa relação poderá ou não evoluir (RUZZARIN; SIMIONOVSCHI, 2010).

Durante a devolutiva da avaliação, o gestor deve acordar um plano de ação com o avaliado, em relação às competências comportamentais ou técnicas que ficaram em níveis de prontidão em desenvolvimento e no nível de prontidão em aplicação. Este plano terá algumas ações de responsabilidade da IES (treinamentos formais, por exemplo) e, especialmente, ações de mudança comportamental por parte do profissional avaliado.

Depois de estruturado, o programa conexões foi implantado por meio de blocos de intervenção, sendo o primeiro o da sensibilização. Neste momento, se apresentam os motivos que justifiquem a implantação dos novos processos na empresa, com o objetivo de esclarecer os conceitos de competências, os benefícios da adoção deste modelo e, com isso, obter mais facilmente a adesão das pessoas (GRAMIGNA, 2002; LEME, 2006).

Para uma melhor compreensão dos profissionais em relação às competências essenciais, foi elaborada uma peça publicitária, contextualizando cada competência essencial. Este material ficou exposto em cartazes nos murais espalhados na IES, tela de computador e e-mail dos profissionais, a fim de divulgar as competências requeridas pela Faculdade Brasil, reforçando a importância da adesão de todos por meio da comunicação do novo modelo (KOCHANSKI, 1997; GRAMIGNA, 2002; GANGANI; MCLEAN; BRADEN, 2006).

Houve, ainda, a comunicação oficial do programa em um evento da Faculdade Brasil que reuniu 285 profissionais da empresa. Neste momento, foi entregue a cartilha com a contextualização do programa, além de ser reforçada pelo diretor geral a política estratégica da IES, por meio de sua missão, visão e valores, e a importância deste novo modelo de gestão para o crescimento da IES. Este evento proporcionou o compartilhamento e visão sistêmica do programa para os envolvidos, reforçando a importância da comunicação em um processo de mudança organizacional (GRAMIGNA, 2002; GANGANI; MCLEAN; BRADEN, 2006).

Para a implantação do modelo, o envolvimento dos empregados foi essencial. A apresentação da proposta fez diferença porque ela "tem que ser de forma muito empática, convencer que esse projeto é realmente bom e que possa dar certo, senão não adianta" (E3). Assim, "se as pessoas não estão convencidas e não querem ser convencidas da importância da proposta, o projeto das políticas não avançam, elas ficam naquela esfera abstrata de cumprir uma função" (E3).

A sensibilização e capacitação das lideranças também foi necessária para que estes entendessem a mudança de paradigma que um modelo de GP com base na gestão por competências traria para a IES. O treinamento para todos os profissionais deu-se por meio de grupos divididos por departamentos e cursos, conduzido pela GP da IES. Neste momento, foram apresentados os conceitos de cada competência, o mapa de competências, os níveis de prontidão e as trilhas de carreira. Isto foi importante, pois quando o "gestor tem um pouco mais de clareza das políticas, ele consegue transmitir um pouco melhor para seus colaboradores, a ponto de aderir a ideia, comprar a ideia" (E3).

Também foram proporcionados momentos para debates e dirimir as dúvidas, em que os profissionais puderam expressar seus anseios e questionamentos a respeito do que foi apresentado e o impacto do programa no seu cotidiano de trabalho. No entanto, o E3 ressalta que nos encontros "as pessoas não falam ou não se envolvem, fica muito no anonimato, olhando no relógio o tempo pra ir embora, não generalizando, mas boa parte das pessoas no meu ponto de vista não compraram a ideia". 
Mesmo com a sensibilização realizada, alguns empregados "ficaram meio assustados, tudo que é novo gera uma certa insegurança e isso foi normal" (E3). A descrição de cargos com base nas competências foi uma política que gerou desconforto, pois "muitos não se sentiram enquadrados, achavam que tinham que estar em outra função, acham que fazem mais que os outros" (E2). Este contexto é coerente com as resistências de mudanças apontadas por Marques et al. (2014) e Marques, Borges e Reis (2016).

O entendimento das competências foi o que gerou mais estranhamento para os empregados - "no primeiro ano foi bem difícil, esse entendimento das competências" (E1). Tanto os professores como o administrativo tiverem dificuldade de "entender como seria ser avaliado pela competência empreendedorismo" (E1), mostrando que os conceitos que envolvem a gestão por competências não é uma linguagem comum a todos (GANGANI; MCLEAN; BRADEN, 2006). Os professores também "não aceitaram muito bem a ideia de serem avaliados por competências" (E1), gerando assim uma resistência "principalmente, na área acadêmica, que teve muita pressão pra desqualificar o processo em vez de querer melhorar" (E6), ratificando os achados de Marques et al. (2014) e Marques, Borges e Reis (2016) em relação às resistências encontradas ao propor algo novo nas organizações.

O E7 ressalta ainda que "os professores do meu curso, uns receberam bem, mas a maioria recebeu como punição, mas tudo depende como você conduz. Eu como líder tenho obrigação de conduzir que as pessoas entendam". Este relato mostra a importância do gestor na condução do feedback para que ele tenha um papel positivo no processo.

A avaliação de desempenho com base na gestão por competências teve um impacto nos empregados, pois "ninguém gosta de ser avaliado e avaliar o outro" (E2), mostrando que o modelo de gestão por competências demanda uma mudança de pensamento das organizações, principalmente, em relação ao foco da GP tradicional em propor políticas e práticas com base no controle e não no desenvolvimento dos empregados (DUTRA, 2014). Assim, alguns empregados acharam que era "um processo punitivo, processo para demitir professores. As pessoas não compreendem que é um processo de aprendizado, não gostam de ser avaliados" (E7). O E3 complementa essa percepção: "se as pessoas entendessem que a proposta, o projeto justamente é uma possibilidade de crescimento, uma oportunidade de melhoria também para o sujeito e não só para instituição, nós teríamos avançado muito mais, e termos de compreensão, de aplicabilidade".

O hábito de realizar o feedback gerou impacto na IES, "não só para questão financeira porque ela está descolada do financeiro, então, esse entendimento, as pessoas se movem só por dinheiro e não é, é para teu desenvolvimento pessoal" (E2). A GP tradicional ao propor políticas e práticas de controle criou uma postura passiva dos empregados (DUTRA, 2014), enquanto a gestão por competências emerge para proporcionar que o empregado tenha autonomia quanto ao seu desenvolvimento. Nesse sentido, o E5 relata como o feedback acrescentou no seu desenvolvimento:

\footnotetext{
Eu detectei dificuldades que eu tinha e carregava na minha gestão que precisavam ser melhorados. Eu recebi feedback da direção, de outros setores, para tentar me ajudar. Com isso, fez com que eu crescesse no meu cargo que eu exerço hoje. Então, eu posso te dizer que quando eu cheguei e hoje como eu estou foi uma caminhada dentro da instituição e eu como pessoa, se não fosse a GP embasada com ferramentas, talvez eu não tivesse feito essa caminhada. Se eu fizer um balanço disso, para mim, foi altamente produtivo ter feito essas capacitações, ter participado com o pessoal, ter dividido isso porque me potencializou.
}

A partir dessas mudanças, "deu pra perceber quem estava dentro da proposta, quem tinha a perspectiva de permanecer na Faculdade Brasil mais tempo, formar uma carreira, ter 
A implantação de um modelo de gestão de pessoas com base na gestão por competências em uma instituição de ensino superior privada

uma permanência maior e aquelas pessoas que já estavam mais pra lá do que pra cá, já estavam buscando outras coisas" (E3). Nesse sentido, alguns empregados sentiram que podiam progredir na carreira, pois "a Faculdade Brasil conseguiu reconhecer os profissionais daqui" (E4), visto que o "projeto justamente é uma possibilidade de crescimento, uma oportunidade de melhoria também para o sujeito e não só para instituição" (E3), corroborando os pressupostos da gestão por competências com base no desenvolvimento do empregado (DUTRA, 2014).

Conforme o modelo foi implantado, as resistências diminuíram, pois, "a segunda rodada de avaliação já foi bem mais light, as pessoas entendiam que não era um bicho de sete cabeças" (E7). Os relatos mostram que as principais dificuldades encontradas foram em "mudar o hábito de se fazer cumprir as regras" (E4), sendo que esta foi um dos principais motivos que incentivou a implantação de um modelo de GP para IES: padronizar os processos para que os empregados tivessem um tratamento mais justo. Uma das dificuldades encontradas foi conseguir manter as "políticas nos primeiros tempos. Tipo, recrutamento: primeiro é interno, para depois abrir externo. Só que tinha gestor: 'ah, eu não estou com muito tempo, vou abrir interno e externo ao mesmo tempo'”. Na mesma direção, a política de integração também não é realizada por parte dos gestores, como relata a E1:

\footnotetext{
Tem a parte da GP que, quando a pessoa entra, tem uma tarde com a GP para a gente explicar tudo como funciona, como que funcionam as políticas, como que funciona missão, visão e valores, como que funciona planejamento, sistema. Enfim, a gente dá um panorama assim da Faculdade Brasil. E o gestor tem também um papel nesse processo que é apresentar a equipe, explicar como que funciona o setor, como que funciona o curso, mostrar a estrutura e tal e essa é parte que às vezes não acontece, a parte que o gestor é responsável. Então, essa é outra política que tem, não resistência, mas que eles acabam não praticando.
}

Pelo exposto, mostrou-se que a implantação de um modelo de gestão por competências em uma IES privada passou por diversas etapas e ajustes (Figura 5) para que o modelo pudesse ser aplicado e atendesse as necessidades da IES e dos seus empregados. 
Larissa Nardes, Shalimar Gallon, Elaine Taufer e Betina Magalhães Bitencourt

Figura 5 - Etapas da Implantação do modelo de gestão por competências em uma IES privada

\begin{tabular}{|c|}
\hline Crescimento muito rápido \\
\hline Necessidade do modelo para profissionalizar a gestão \\
\hline Necessidade de Padronização dos procedimentos \\
\hline Descrever os procedimentos \\
\hline Desenvolvimento das estratégias organizacionais \\
\hline Mapear as competências essenciais \\
\hline Reuniões para desenvolver as políticas \\
\hline Envolver pessoas de diferentes áreas \\
\hline Implantação do modelo \\
\hline Alterações das políticas conforme o modelo é aplicado \\
\hline Divulgação das políticas \\
\hline Sensibilização e capacitação dos empregados sobre o novo modelc \\
\hline Aplicação do primeiro ciclo de avaliação por competências \\
\hline Identificar pontos de resistências e melhorias a serem realizadas \\
\hline Aplicação do segundo ciclo de avaliação por competências \\
\hline Identificar pontos de resistência e melhorias a serem realizadas \\
\hline
\end{tabular}

\title{
4.4 O MODELO E SEUS DESAFIOS
}

Os entrevistados sentem a necessidade de um próximo ciclo de aplicação da gestão por competências e "que talvez precise de outras ferramentas para dar conta de um processo de gestão, fazendo parte do próprio processo de evolução da empresa" (E2), pois a Faculdade Brasil mudou e o modelo necessita ser revisado, como relata o E2:

\begin{abstract}
Quando a gente começou só tinha graduação e pós, hoje nós temos graduação, pós, programa de mestrado e os seis programas de mestrados estão com 70 doutores recém formados, com expectativas tanto de remuneração, como progressão, de carreira, enfim, tudo isso mexeu muito, na época que a gente discutiu nem tinha na nossa estratégia programas de mestrado e hoje estamos com seis, entende que o perfil de contratação mudou completamente, então acredito que no próximo período precisa urgentemente rever essas políticas e olhar muito mais pros rumos da Faculdade Brasil nos próximos cinco anos.
\end{abstract}

As políticas foram implantadas, porém, "tem uma validade, a gente ficou um tempo sem olhar para elas e agora a gente vai ter quer voltar, tem coisa que não tem mais efeito. Então, tem várias que precisam ser refeitas, melhoradas a sua estrutura" (E6). O modelo foi amadurecendo, porém, "muita coisa a gente não conseguiu manter e muita coisa todo ano a gente precisa dar uma revisada porque todo ano a Faculdade Brasil está se modificando" (E4). Este depoimento corrobora os apontamentos de Tanure, Evans e Pucik (2007) ao apontarem 
A implantação de um modelo de gestão de pessoas com base na gestão por competências em uma instituição de ensino superior privada

que as políticas e práticas de GP devem ser alteradas quando ocorrem mudanças na organização a fim de ter uma estrutura intimamente conectada.

A cada ciclo de avaliação anual é gerado um ciclo de aprendizado constante para todos os níveis da organização, na medida em que as reflexões sobre carreira e desenvolvimento são temas de diálogos para a criação de uma cultura de aprendizagem que transforma a IES por meio das pessoas. Os resultados obtidos no primeiro ciclo serviram como base para estruturar os programas de educação continuada, modelo que está sendo aprimorado para, cada vez mais, atuar nas necessidades identificadas pelos gestores nas avaliações, suportando, assim, o desenvolvimento sustentável das equipes, com foco nas necessidades da IES.

Ao final do primeiro ciclo constatou-se a necessidade de rever o programa de desenvolvimento dos gestores, denominado 'acelerar', visto as demandas geradas para aperfeiçoamento dos líderes. Também há demanda para que a avaliação de desempenho seja realizada de forma mais ampla, pois "a avaliação por competências é $180^{\circ}$. A ideia é pro ano que vem fazer $360^{\circ \prime \prime}$ (E1). Também foi enfatizada a necessidade de aprimorar o processo de comunicação, buscando maior entendimento em relação ao sistema, e focar na desmistificação das competências, como simplicidade e facilidade de compreensão mostrando a importância da comunicação da implantação de um modelo (GANGANI; MCLEAN; BRADEN, 2006) para evitar a resistência dos empregados (MARQUES; BORGES; REIS, 2016).

Embora, tenha "gente [que] ainda não goste disso, não queira fazer" (E1), alguns empregados veem as políticas de GP de uma forma positiva, como relata o E5: "gostaria que a Faculdade Brasil continuasse com os programas, com essa avaliação de competências que eu acho extremamente importante e com esse programa acelerar que acelera líderes". No entanto, o modelo desenvolvido pela IES ainda gera desafios para os gestores, pois "boa parte das pessoas não compraram a ideia" (E3), principalmente na parte acadêmica, que "ainda sofre algumas resistências" (E6).

Um desafio para o modelo de GP implantado é a questão do plano de carreira dos empregados mais jovens, pois eles "tem uma pressa de progredir, não tem muita paciência de esperar tanto tempo para chegar lá" (E2). Dessa maneira, o desafio hoje "não é nem saber se o nosso modelo está certo ou não, mas sim ter um modelo certo para o momento, as pessoas não querem progredir devagar, elas querem se enxergar lá na frente" (E2). Nesse sentido, "é preciso buscar uma política que dê conta dessas diferenças de necessidades que as pessoas têm, como elas se enxergam num projeto e no momento que você engessa muito, na primeira oportunidade elas vão sair" (E2).

Destaca-se que um dos diferenciais elencados pelos entrevistados para o crescimento da IES foi justamente o fato de terem empregados jovens e dinâmicos na equipe. Este é o perfil encontrado em grande parte dos empregados das IES privadas, muitas vezes, seus próprios alunos. Porém, em se tratando de estabelecer critérios definidos para o plano de carreira, isso se tornou um possível entrave e um ponto de resistência ao modelo, uma vez que estes trabalhadores apresentam desejo de ascensão na carreira, muitas vezes, acelerado e esperam que as organizações contemplem isso. Assim, surge a demanda por conciliar os diferentes momentos que cada empregado está na IES, como relata o E3:

Quando você tem um grupo, no caso de professor, uma estabilidade maior, uma permanência maior de instituição, isso facilita, você inicia o processo de implementação e vai melhorando o processo, essas pessoas que te acompanham nesse processo, elas também vão progredindo, vão evoluindo e de certa forma ajudam qualificar o programa e a proposta, agora quando a gente começa a contratar muita gente nova, trocar pessoas de setores, enfim, isso gera um

RGO - Revista Gestão Organizacional, Chapecó, v. 14, n. 2, p. 69-94, maio/ago. 2021. 
Larissa Nardes, Shalimar Gallon, Elaine Taufer e Betina Magalhães Bitencourt

descompasso, porque você tem lá um sujeito com nível de compreensão $\mathrm{x}$ e outro com nível de compreensão y, aí essas pessoas acabam se atritando [...]. Então, eu vejo que uma das dificuldades é a compreensão, devido os diferentes momentos que as pessoas se encontram dentro da instituição, o que é normal, porque não tem como manter um grupo permanente até porque não é uma instituição pública e até uma pública tem rotatividade de pessoas, mas, no nosso caso, eu vejo que a mudança é significativa.

Apesar dos desafios expostos, os entrevistados entendem que o modelo implantado pela Faculdade Brasil "foi bem-sucedido, bem desenhado, bem estruturado e está passando de certa forma por um processo de aplicação tranquila" (E3), "de acordo com o esperado" (E1). A IES "acertou muito nas políticas" (E4) e "hoje todas elas estão implantadas, sempre numa crescente melhoria" (E2). Este êxito pode estar atrelado ao desenvolvimento de políticas de GP que "fecham uma visão estratégica da GP" (E2), corroborando os pressupostos de um GP estratégica interligada com a estratégia da organização (ULRICH, 2000; ALMEIDA et al., 2013; DUTRA, 2014). Essas políticas implicaram em uma mudança na IES como um todo, pois tinham como base "um olhar sistêmico do todo que estava de acordo com a estratégia da empresa. No meu ponto de vista, o sucesso das políticas se deu porque elas sempre estiveram grudadas na estratégia da empresa" (E2). Na percepção do E6, essas modificações acarretaram acontecimentos positivos:

\footnotetext{
Toda essa caminhada nos levou a ter um estilo de gestão que é respeitado, não única e exclusivamente, mas sair em uma revista Exame como uma das instituições que mais cresce no país, ganhar por ano consecutivo nas melhores empresa pra se trabalhar, ter um clima organizacional bom nesse período, com oscilações como toda empresa tem, elas são frutos dessa construção, sempre quando a gente vai pensar futuro, a gente tem que olhar o estágio atual que nós temos, o que damos conta pra gente chegar lá.
}

Por todo exposto, o modelo mostra a atuação da GP com uma atuação estratégica. O E5 observa que a Faculdade Brasil investiu nesta área, diferentemente das demais IES, pois, "não são todas as instituições que fazem isso, não optam por isso, instrumentalizar de uma forma muito profissional a gestão" (E5), conforme já evidenciado por Quel (2008). A GP da IES necessitava de modificações, dessa maneira, "ela se tornou estratégica a partir da definição da direção, que era uma área que íamos investir, porque a gente acredita que através das pessoas iria fazer a mudança, iria formar novas lideranças" (E2). Os resultados corroboram os achados de Rejasmuslera, Urquiza e Cepeda (2012), os quais mostram que uma das vantagens do modelo é o alinhamento da GP com a estratégia da empresa e com a estratégia dos GP e o fortalecimento das lideranças em relação às definições de GP. Assim, os resultados da implantação de um modelo de GP mostram como a área pode se tornar estratégica e dar um diferencial competitivo para uma organização que deseja ter destaque no mercado.

\section{CONSIDERAÇÕES FINAIS}

A GP tem passado por vários desafios, principalmente na busca de mostrar a sua atuação estratégica com vistas a dar suporte ao negócio. A fim de mostrar a sua contribuição e preencher as lacunas da literatura sobre a elaboração de componentes e estruturas da GP (LENGNICK-HALL et al., 2009; ARMOND et al., 2016), este estudo buscou analisar o desenvolvimento e implantação de um modelo de Gestão de Pessoas com base na gestão por competências em uma IES privada.

Os resultados mostram que o modelo facilitou a tarefa de gerenciar, possibilitando mais justiça e coerência no trato com as pessoas e eliminando parte da subjetividade inerente 
A implantação de um modelo de gestão de pessoas com base na gestão por competências em uma instituição de ensino superior privada

aos processos de avaliação, uma vez que se considerou o sistema como facilitador no processo de orientação aos profissionais, no que diz respeito às oportunidades de carreira e à priorização de programas de capacitação. Ademais, o comprometimento e o forte amadurecimento nos processos de GP possibilitaram o fortalecimento dos gestores com uma visão ampliada de suas equipes, a fim de norteá-los na condução de feedback, comunicação, rendimento profissional e na sugestão de mudanças, além de estreitar a relação entre o profissional e o gestor. O modelo se revelou não somente um modelo de GP com base na gestão por competências, mas um motivador para crescimento profissional e pessoal, atuando como agente de mudança nos diferentes contextos por meio de seus profissionais.

O modelo proposto tem como diferencial a possibilidade de lidar com diferentes categorias de empregados: gestores, técnicos-administrativos e professores. Estes últimos são regidos e avaliados por normativas educacionais que não cabem aos outros empregados, como por diretrizes do MEC e da CAPES. Assim, além de ter que se levar em consideração as metas organizacionais do negócio que, em grande parte, é responsabilidade dos técnicosadministrativos (como metas de vendas, captação de alunos, diminuição de inadimplência, entre outros), também tinha que se levar em consideração o desempenho dos professores nas aulas, no impacto na nota do ENADE, na pontuação da CAPES, no conceito dos programas de pós-graduação Stricto Sensu, no impacto social, na captação de recursos por meio de consultorias e na aprovação de projetos de pesquisa. Ademais, alguns professores também são convidados a atuar em cargos de gestão (como coordenador de curso). Então, era necessário um modelo de contemplasse toda essa dinamicidade das IES.

Neste sentido, o modelo se mostrou um desafio ao buscar convergir estas diferenças, mas, ao mesmo tempo, buscar ressaltar as possibilidades de crescimento de todos os empregados. Isto foi possível em função do modelo ter sido delineado com base na gestão por competências. A partir das competências essenciais, foram criadas diretrizes amplas para todos os empregados que convergissem com o negócio da empresa. Ao mesmo tempo, as competências foram adaptadas para atender aos diferentes critérios de cada área de atuação.

Este estudo mostra a importância de se ter um modelo de GP com políticas e práticas articuladas entre si para que os resultados possam convergir de acordo com os objetivos organizacionais. Além disso, a partir da narrativa dos passos da implementação deste programa, é possível utilizar este estudo como ferramenta de benchmarking a outras organizações que desejam alcançar tal intento e como método para fins didáticos.

O estudo contribui, ainda, para mostrar a importância da GP para as empresas, pois esta área, por vezes, é vista como meramente operacional, sem influência estratégica. A dificuldade de se ter políticas e práticas para os processos da GP pode ser vista, não necessariamente, como uma negligência da área. Muitas vezes, está relacionado com a importância que a empresa dá para os seus processos e permite que a GP mostre a diferença que ela pode fazer para a organização, a qual frequentemente a sua legitimidade está condicionada à comprovação matemática de sua efetividade (BARBOSA, 2009). Isso mostra que a problemática da GP ultrapassa suas políticas e práticas, pois envolve a maneira como a área está posicionada estrategicamente na organização e a maneira que ela atua para ter tal destaque (GALLON et al., 2013).

\section{REFERÊNCIAS}

ALMEIDA, E. S.; COSTA, D. V. F.; ALTAF, J. G.; CASTRO, D. R.; TROCCOLI, I. R. Gestão de pessoas como estratégia: um estudo de caso em uma empresa de telefonia de Juiz de Fora. 
Revista de Carreiras e Pessoas, São Paulo, v. 3, n. 2, p. 54-70, 2013. DOI: https://doi.org/10.20503/recape.v3i2.16534.

ARMOND, L. P.; CÔRTES, F. G.; SANTOS, F. A. M.; DEMO, G.; MENESES P. P. Gestão estratégica de pessoas: revisão da produção nacional de 2006 a 2015 e agenda de pesquisa para o contexto brasileiro. In: Encontro da Associação Nacional de Pós-Graduação e Pesquisa em Administração, 40, 2016, Costa do Sauipe. Anais eletrônicos [...]. Costa do Sauipe: ANPAD, 2016. Disponível em:

http://www.anpad.org.br/eventos.php?cod_evento=1\&cod_edicao_subsecao $=1302 \&$ cod_e vento_edicao=83\&cod_edicao_trabalho=21778 Acesso em: 09 nov. 2020.

BARBOSA, A. C. Q. Gestão de recursos humanos: realidade atual e perspectivas. In: SILVA, J. R.; BARBOSA, A. C. Q. (Orgs). Estado, Empresas e Sociedade: Um Mosaico Luso-Brasileiro. Lisboa: Edições Colibri, 2009. p. 15-30.

BARDIN, L. Análise de Conteúdo. 3. ed. Lisboa, Portugal: Edições 70, 2009.

BRANDÃO, H. P.; ZIMMER, M. V.; PEREIRA, C. G.; MARQUES, F.; COSTA, H. V.; CARBONE, P. P.; ALMADA, V. F. de. Gestão de desempenho por competências: integrando a gestão por competências, o balanced scorecard e a avaliação 360 graus. Revista de Administração Pública, Rio de Janeiro, v. 42, n. 5, p. 875-898, 2008. DOI: http://dx.doi.org/10.1590/S003476122008000500004.

DE RÉ, C. A.; DE RÉ, M. A. Processos do sistema de gestão de pessoas. In: BITENCOURT. C. (org.) Gestão Contemporânea de Pessoas. Porto Alegre: Editora Bookman, 2011. p. 79-100.

DRAGANIDIS, F.; MENTZAS, G. Competency based management: a review of systems and approaches. Information Management \& Computer Security, v. 14, n. 1, p. 51-64, 2006. DOI:10.1108/09685220610648373.

DUTRA, J. S. Gestão de pessoas. Modelo, processos, tendências e perspectivas. São Paulo: Atlas, 2002.

DUTRA, J. Competências: Conceitos e instrumentos para a gestão de pessoas na empresa moderna. São Paulo, Atlas, 2014.

FIOREZE, C. A gestão das IES privadas sem fins lucrativos diante dos tensionamentos da mercantilização da educação superior e o caso das universidades comunitárias regionais: a caminho do hibridismo? Revista Brasileira de Estudos Pedagógicos, Brasília, v. 101, n. 257, p. 79-98, 2020. DOI: https://doi.org/10.24109/2176-6681.rbep.101i257.4356.

FLEURY M. T.; FLEURY, A. Alinhando estratégias e competências. Revista de Administração Eletrônica, São Paulo, v. 4, n. 1, p. 44-57, 2004. DOI: http://dx.doi.org/10.1590/S003475902004000100012.

GALLON, S.; BITENCOURT, B. M.; CAMILLIS, P. K.; SCHEFFER, A. B. B. Gestão de Pessoas: o que andam falando por aí? Uma metanálise sobre os estudos de Gestão de Pessoas na área de produção. Revista Sociais e Humanas, Santa Maria, v. 26, n. 3, p. 588-607, set./dez. 2013.

GANGANI, N.; MCLEAN, G. N.; BRADEN, R. A. A competency-based human resource development strategy. Performance Improvement Quarterly, v. 19, n. 1, p. 127-140, 2006. DOI: https://doi.org/10.1111/j.1937-8327.2006.tb00361.x. 
A implantação de um modelo de gestão de pessoas com base na gestão por competências em uma instituição de ensino superior privada

GRAMIGNA, M. R. Modelo de Competências e Gestão de Talentos. São Paulo: Makron Books, 2002.

GRANT, R. M. The resource-based theory of competitive advantage: implications for strategy formulation. California Management Review, v. 33, n. 3, p. 114-135, 1991. DOI: https://doi.org/10.2307/41166664.

INSTITUTO NACIONAL DE ESTUDOS E PESQUISAS EDUCACIONAIS ANÍSIO TEIXEIRA (INEP). Sinopse Estatística da Educação Superior 2019. Brasília: Inep, 2020. Disponível em http://portal.inep.gov.br/basica-censo-escolar-sinopse-sinopse. Acesso em: 09 nov. 2020.

LEME, R. Avaliação de desempenho com foco em competência: a base para remuneração por competências. Rio de Janeiro: Qualitymark, 2006.

LENGNICK-HALL, M. L.; LENGNICK-HALL, C. A.; ANDRADE, L. S.; DRAKE, B. Strategic human resource management: the evolution of the field. Human Resource Management Review, v. 19, p. 64-85, 2009.

LIMA, M. G.; NORO, G. B. Gestão de Competências docentes: um estudo no Centro Universitário Franciscano. Disciplinarum Scientia, Santa Maria, v. 4, n. 1, p. 91-110, 2008.

KOCHANSKI, J. Competency-based management. Training and development, v. 51, n. 10, p. 41-44, 1997.

MARQUES, A. L.; BORGES, R.; MORAIS, K.; SILVA, M. C. Relações entre resistência a mudança e comprometimento organizacional em servidores públicos de Minas Gerais. Revista de Administração Contemporânea - RAC, v. 18, n. 2, p. 161-175, 2014. DOI: https://doi.org/10.1590/S1415-65552014000200004.

MARQUES, A. L.; BORGES, R.; REIS, I. do C. Mudança organizacional e satisfação no trabalho: um estudo com servidores públicos do estado de Minas Gerais. Revista de Administração Pública, Rio de Janeiro, v. 50, n. 1, p. 41-58, 2016. DOI: https://doi.org/10.1590/00347612131034.

MUKHOPADHYAY, K.; SIL, J. A competency based management system for sustainable development by innovative organizations a proposal of method and tool. Vision-The Journal of Business Perspective, v. 15, n. 2, p. 153-162, 2011.

QUEL, L. F. Alinhamento de competências em instituições de ensino superior: um estudo de caso na rede privada. Revista de Gestão USP, v. 15, p. 63-74, 2008.

REJAS-MUSLERA, R.; URQUIZA, A.; CEPEDA, I. Competency-Based model through it: an action research project. Systemic Practice and Action Research, New York, v. 25, n. 2, p. 117-135, 2012.

RIBEIRO, A. R. S.; MARTINS, P. R.; NETA, M. do C. S. Metas organizacionais e gestão estratégica de pessoas: estudo de caso em instituição financeira. Revista de Carreiras e Pessoas, São Paulo, v. 7, n. 2, p. 544-563, 2017. DOI: https://doi.org/10.20503/recape.v7i2.32751.

RICHEY, B.; WALLY, S. Strategic human resource strategies for transnationals in Europe. Human Resource Management, v. 8, n. 1, p. 79-97, 1998. DOI: https://doi.org/10.1016/S1053-4822(99)80040-0. 
RODRIGUES, J. Remuneração e competências: retórica ou realidade. Revista de Administração Eletrônica, v. 46, edição especial, p. 23-34, 2006. DOI: https://doi.org/10.1590/S0034-75902006000500002.

ROHM, R. H. D.; LOPES, N. F. O novo sentido do trabalho para o sujeito pós-moderno: uma abordagem crítica. Cadernos EBAPE.BR, v. 13, n. 2, p. 332-345, 2015. DOI: https://doi.org/10.1590/1679-395117179.

ROWE, D. E. O.; BASTOS, A. V. B. Vínculos com a carreira e produção acadêmica: comparando docentes de IES públicas e privadas. Revista de Administração Contemporânea, v. 14, n. 6, p. 1011-1030, 2010. DOI: https://doi.org/10.1590/S141565552010000700003 .

RUZZARIN, R.; SIMIONOVSCHI, M. Competências: uma base para a Governança Corporativa. Porto Alegre, AGE, 2010.

SCHULER, R. S. The internationalization of human resource management. Journal of International Management, v. 6, p. 239-260, 2000.

SILVA, C. M. A gestão de competências e sua influência na implementação da gestão estratégica de pessoas: estudo de caso. 2003. Dissertação (Mestrado em Administração) Faculdade de Economia, Administração e Contabilidade, Universidade de São Paulo: São Paulo, 2003.

SILVA JÚNIOR, A.; POLIZEL, C. E. G; SOUZA, S.; SILVA, A. R. L.; SILVA, P. de O. M.; SOUZA, S. P. Políticas públicas para a educação superior: a avaliação, a regulação e a supervisão de IES privadas em debate. Ensaio: avaliação e políticas públicas em Educação, Rio de Janeiro, v. 22, n. 82, p. 215-240, 2014. DOI: https://doi.org/10.1590/S0104-4036201400010001.

TANURE, B.; EVANS, P.; PUCIK, V. A Gestão de Pessoas no Brasil. Virtudes e pecados capitais. estudos de caso. Rio de Janeiro: Elsevier, 2007.

TRIPATHI, K.; AGRAWAL, M. Competency based management in organizational context: a literature review. Global Journal of Finance and Management, India. v. 6, n. 4, p. 349-356, 2014.

UBEDA, C. L.; SANTOS, F. C. A. Os principais desafios da gestão de competências humanas em um instituto público de pesquisa. Gestão de Produção, São Carlos, v. 15, n.1, p. 189-199, 2008. DOI: http://dx.doi.org/10.1590/S0104-530X2008000100016.

ULRICH, D. Introdução. In: ULRICH, D. (org.) Recursos Humanos Estratégicos. Novas perspectivas para os profissionais de RH. São Paulo: Editora Futura, 2000. p. 7-32.

YIN, R. K. Estudo de Caso: planejamento e métodos. 3. ed. Porto Alegre: Bookman, 2010.

ZARIFIAN, P. O modelo da competência: trajetória histórica, desafios atuais e propostas. Editora Senac, São Paulo, 2002. 